\title{
The Anisotropic High Thermoelectric Performance in $\left(\mathrm{Bi}_{x} \mathrm{Sb}_{1-x}\right)_{2} \mathrm{Te}_{3}$
}

\author{
D. Li", X. Y. Qin", X. G. Zhu, J. Zhang*, C. J. Song, H. X. Xin, X. F. Wang
}

Key Laboratory of Materials Physics, Institute of Solid State Physics Chinese Academy of Sciences, 230031 Hefei, P. R. China

\section{Abstract}

The anisotropy of thermoelectric properties for $\left(\mathrm{Bi}_{\mathrm{x}} \mathrm{Sb}_{1-\mathrm{x}}\right)_{2} \mathrm{Te}_{3}(0.16 \leq \mathrm{x} \leq 0.24)$ are investigated in the temperature range of $300 \mathrm{~K}$ to $523 \mathrm{~K}$. Anisotropy ratiosof the specimens are around $0.72-0.93$ and $1.0-1.26$ for the resistivity and the thermal conductivity, respectively. In addition, a relation of $\mathrm{k}_{\perp} \approx \mathrm{k}_{/ /} /(1-f)$ is found to hold, suggesting the validity of the rule of mixture for its $\mathrm{k}$ and $f$. The maximum $\mathrm{ZT}=1.37$ (at $416 \mathrm{~K})$ are achieved for $\left(\mathrm{Bi}_{0.16} \mathrm{Sb}_{0.84}\right)_{2} \mathrm{Te}_{3}$. Besides, $\left(\mathrm{Bi}_{\mathrm{x}} \mathrm{Sb}_{1-\mathrm{x}}\right)_{2} \mathrm{Te}_{3}$ sample shows good mechanical properties. The compression strength for $\left(\mathrm{Bi}_{0.16} \mathrm{Sb}_{0.84}\right)_{2} \mathrm{Te}_{3}$ is $60 \mathrm{MPa}$ and $65 \mathrm{MPa}$ in the two measured directions, which is 6 folds and 1.6 times as larger as that of commercial ingot parallel and normal to the solidification direction, respectively.

\section{Introduction}

Thermoelectric (TE) materials are among the important potential candidates for alternative and complementary sources for energy, wherein heat can be directly converted into electrical energy and vice versa [1]. Efficient TE materials should exhibit a high thermoelectric figure of merit defined as $\mathrm{ZT}=\mathrm{S}_{2} \mathrm{~T} /(\rho \kappa)$, where $\mathrm{T}, \mathrm{S}, \rho$, and $\kappa$ are the absolute temperature, Seebeck coefficient, electrical resistivity and thermal conductivity, respectively [2]. Among the traditional thermoelectric materials, $\mathrm{Bi}_{2} \mathrm{Te}_{3}$-based materials, including p-type $\left(\mathrm{Bi}_{\mathrm{x}} \mathrm{Sb}_{1-\mathrm{x}}\right)_{2} \mathrm{Te}_{3}$ and $\mathrm{n}$-type $\mathrm{Bi}_{2} \mathrm{Te}_{3-\mathrm{y}} \mathrm{Se}_{\mathrm{y}}$, are well known as the most efficient TE materials that operate near room temperatures $[3,4]$ $\mathrm{Bi}_{2} \mathrm{Te}_{3}$ has a rhombohedra structure with the space group $\mathrm{R} \overline{3} \mathrm{~m}$. Along the $\mathrm{c}$-axis, the atom layers array in the structure of $-\mathrm{Te}(1)-\mathrm{Bi}-\mathrm{Te}(2)$ $\mathrm{Bi}-\mathrm{Te}(1)-$; the $-\mathrm{Te}(1)-\mathrm{Te}(1)$ - atomic layers are bonded by the weak van der Waals force, so they are liable to cleavage [5]. Originating from this unique structural anisotropy, anisotropies in resistivity and thermal conductivity are observed for $\mathrm{Bi}_{2} \mathrm{Te}_{3}$-based compounds [69]. The experiments suggest that the anisotropy ratios range from 4.3 to 6.7 for the resistivity, and 2.1 to 2.5 for the thermal conductivity. Due to the isotropy for Seebeck coefficient, ZT along the cleavage planes is approximately twice to three times as large as that along the $\mathrm{c}$-axis. The anisotropic characteristics of ZT will inevitably result in reduced efficiency in utilization of $\mathrm{Bi}_{2} \mathrm{Te}_{3}$-based alloys. On the other hand, $\mathrm{Bi}_{2} \mathrm{Te}_{3}$-based alloys with high structural anisotropy have poor mechanical properties due to cleavage fractures, which causes problems in cutting or/and operating the material. Hence, it is of vital significance to obtain highly isotropic superior thermoelectric performance for anisotropic $\mathrm{Bi}_{2} \mathrm{Te}_{3}$-based alloys with good mechanical properties for large-scale commercial applications.

Several methods have been used to obtain isotropic $\mathrm{Bi}_{2} \mathrm{Te}_{3}$-based bulk materials. For example, by sintering nano-sized spherically shaped powder synthesized via chemical reaction method, Kim et al. [6] obtained isotropic p-type $\mathrm{Bi}_{0.5} \mathrm{Sb}_{1.5} \mathrm{Te}_{3}$ bulk sample that had no directional difference in TE properties, and the ZT value of 1.1 in both parallel and normal to the consolidated direction was obtained. Through ball milling and hot pressing of $\mathrm{Bi}_{2} \mathrm{Te}_{3}$-based n-type single crystals, isotropic $\mathrm{ZT}$ had been achieved for $\mathrm{Bi}_{2} \mathrm{Te}_{2.7} \mathrm{Se}_{0.3}$ bulk sample with the peak ZT of 0.85 in both directions parallel and normal to the pressing direction [8]. Unfortunately, although there have been a few reports related to the preparation of isotropic $\mathrm{Bi}_{2} \mathrm{Te}_{3}$-based alloys, the obtained ZT values for the isotropic materials are not high to meet the requirements of large scale applications. As a matter of fact, to achieve isotropic superior thermoelectric performance for $\mathrm{Bi}_{2} \mathrm{Te}_{3}$-based alloys with good mechanical properties, one needs not only to reduce (or eliminate) the anisotropy in their microstructures, but also to enhance (or maintain) both power factor (PF) and phonon blocking in $\mathrm{Bi}_{2} \mathrm{Te}_{3}$ based alloys. In this aspect, nano-inclusions have been shown to be efficient. They are found to be able to simultaneously scatter the phonons and filter the lower-energy carriers so that both the power factor and thermal conductivity contributions could be synergistically improved $[10,11]$. To our knowledge; however, the attempt to achieve superior thermoelectric performance for $\mathrm{Bi}_{2} \mathrm{Te}_{3}$-based alloys in different measured direction is not successful until today [6].

In the present work, isotropic microstructure and high $\mathrm{ZT}$ are obtained for $\left(\mathrm{Bi}_{\mathrm{x}} \mathrm{Sb}_{1-\mathrm{x}}\right)_{2} \mathrm{Te}_{3}$ with $\mathrm{x}=0.16,0.18$ and 0.20 in the both measured directions. The largest $\mathrm{ZT}=1.37$ (at $416 \mathrm{~K}$ ) are achieved for $\left(\mathrm{Bi}_{0.16} \mathrm{Sb}_{0.84}\right)_{2} \mathrm{Te}_{3}$, which is attributed to both the lowering of $\kappa$ from enhanced phonon scattering due to $\mathrm{Sb}_{2} \mathrm{O}_{3}$ nano-inclusions and the elevated $\mathrm{S}$ via intensified energy filtering effect from interphase potentials. In addition, the compression strength for $\left(\mathrm{Bi}_{0.16} \mathrm{Sb}_{0.84}\right)_{2} \mathrm{Te}_{3}$ in this work is $60 \mathrm{MPa}$ and $65 \mathrm{MPa}$ in the two measured direction, which is six folds and 1.60 times as larger as that of commercial ingot parallel and normal to the directional solidification direction, respectively.

\section{Experimental Section}

\section{Sample preparation}

Elemental Bi (99.99\%, Alfa Aesar), Sb (99.5\%, Sigma Aldrich) and Te $(99.999 \%$, Alfa Aesar) powders are weighted according to the formula of $\left(\mathrm{Bi}_{\mathrm{x}} \mathrm{Sb}_{1-\mathrm{x}}\right)_{2} \mathrm{Te}_{3}(\mathrm{x}=0.16-0.24)$ doped with $3 \mathrm{wt} \% \mathrm{Te}$. The powder mixture is loaded into quartz ampoule sealed under vacuum at $10^{-2} \mathrm{~Pa}$, and then heated at $800^{\circ} \mathrm{C}$ for $10 \mathrm{~h}$. Then the ingots are ground into powder by using a mortar for one hour.

"Corresponding Author: Dr. D. Li, Key Laboratory of Materials Physics, Institute of Solid State Physics Chinese Academy of Sciences, 230031 Hefei, P. R. China; E-mail: lidi@issp.ac.cn

: Dr. X. Y. Qin, Key Laboratory of Materials Physics, Institute of Solid State Physics Chinese Academy of Sciences, 230031 Hefei, P. R. China; E-mail: xyqin@issp.ac.cn

: Dr. J. Zhang, Key Laboratory of Materials Physics, Institute of Solid State Physics Chinese Academy of Sciences, 230031 Hefei, P. R. China; E-mail: zhangjian@issp.ac.cn

Citation: Li D, Qin XY, Zhu XG, Zhang J, Song CJ, et al. (2017) The Anisotropic High Thermoelectric Performance in $\left(\mathrm{Bi}_{x} \mathrm{Sb}_{1-x}\right){ }_{2} \mathrm{Te}_{3}$. Int J Metall Mater Eng 3: 131 doi: https://doi.org/10.15344/2455-2372/2017/131

Copyright: (C) $2017 \mathrm{Li}$ et al. This is an open-access article distributed under the terms of the Creative Commons Attribution License, which permits unrestricted use, distribution, and reproduction in any medium, provided the original author and source are credited. 
Citation: Li D, Qin XY, Zhu XG, Zhang J, Song CJ, et al. (2017) The Anisotropic High Thermoelectric Performance in (Bi $\left.\mathrm{Sb}_{1-\mathrm{x}}\right)_{2} \mathrm{Te}_{3}$. Int J Metall Mater Eng 3: 131. doi: https://doi.org/10.15344/2455-2372/2017/131

Page 2 of 8

The powders about $28 \mathrm{~g}$ are compacted by spark plasma sintering (SPS)at a pressure of $50 \mathrm{MPa}$ in a diameter of $20 \mathrm{~mm}$ graphite mould in vacuum for $5 \mathrm{~min}$. The sintering temperature, heating rate and cooling rate are $673 \mathrm{~K}, 373 \mathrm{~K} / \mathrm{min}$ and $373 \mathrm{~K} / \mathrm{min}$, respectively. After SPS, bulk samples with dimensions of cylinder $20 \mathrm{~mm}$ od $\times 12 \mathrm{~mm}$ length are obtained.

\section{Microstructure characterization}

The sample is characterized by X-ray diffraction (XRD) using Philips X'Pert PRO X-ray diffractometer equipped with graphite monochromatic $\mathrm{Cu} \mathrm{Ka}$ radiation $(\lambda=1.54056 \AA)$. The operation voltage and current are kept at $40 \mathrm{kV}$ and $400 \mathrm{~mA}$, respectively. TEM (transmission electron microscope) observations were performed on a JEOL-F2010 instrument with an acceleration voltage of $200 \mathrm{kV}$. The morphology is characterized by field emission scanning electron microscopy (FESEM; SU8020).

\section{Measurements of thermoelectric properties and mechanical properties}

A commercial four-probe apparatus (ULVAC-RIKO ZEM-3) is applied to measure the electrical resistivity and Seebeck coefficient of the bar samples. The thermal diffusivity $\mathrm{D}$ is obtained by a laser flash method (Netzsch LFA-457) performed on rectangle samples. The specific heat, $C_{p}$, is determined from the DSC measurement (Pyris Diamond DSC, Perkin-Elmer). The thermal conductivity is calculated from $\kappa=\mathrm{DC}_{\mathrm{p}} d$, where $d$ is the density of the sample determined by Archimedes' ${ }^{\mathrm{p}}$ method. The hole concentration at $300 \mathrm{~K}$ is measured using a physical properties measurement system (Quantum Design). The measurements of room-temperature compression strengths of the samples are carried out on Instron 3369.

\section{Results and Discussion}

Figure 1 shows the X-ray diffraction (XRD) patterns of bulk samples sliced normal $(\perp)$ to the pressing direction for $\left(\mathrm{Bi}_{\mathrm{X}} \mathrm{Sb}_{1}\right.$. $\left.{ }_{\mathrm{x}}\right)_{2} \mathrm{Te}_{3}(0.16 \leq \mathrm{x} \leq 0.24)$, respectively. The main diffraction peaks can be indexed to the standard $\mathrm{Bi}_{0.4} \mathrm{Sb}_{1.6} \mathrm{Te}_{3}$ (JCPDS No.72-1836) phase belonging to the rhombohedra structure, and the additional peak located at about $28^{\circ}$ is observed, which is attributed the excessive Te (JCPDS No. 01-1313) added. In order to quantitatively describe the anisotropy of the sample, orientation factor (f) was calculated by the Lotgering method, ${ }^{12} f=\left(\mathrm{P}-\mathrm{P}_{0}\right) /\left(1-\mathrm{P}_{0}\right)$, where $\mathrm{P}$ is the fractional intensity of the (00l) diffraction peak, $\mathrm{P}=\mathrm{I}(00 \mathrm{l}) / \Sigma \mathrm{I}(\mathrm{hkl})$, and $\mathrm{P}_{0}$ is the diffraction intensity of $\left(\begin{array}{lll}0 & \mathrm{l}\end{array}\right)$ peak for isotropic (i.e. no preferred orientation) $\mathrm{Bi}_{0.4} \mathrm{Sb}_{1.6} \mathrm{Te}_{3}$ (JCPDS No.72-1836). Based on the XRD diffractograms, the orientation factor for $\left(\mathrm{Bi}_{\mathrm{x}} \mathrm{Sb}_{1-\mathrm{x}}\right)_{2} \mathrm{Te}_{3}$ sliced normal to the pressing direction $(f)$ is $0.05,0.03,0.11,0.06$ and 0.11 for $\mathrm{x}=0.24$, $0.22,0.20,0.18$ and 0.16 , respectively, as seen Table 1 . The density for samples (as shown in Table 1)basically decreases with decreasing bismuth content. For example, $d$ decreases from $6.68 \mathrm{gcm}^{-3}$ for $\mathrm{x}=0.24$ to $6.51 \mathrm{gcm}^{-3}$ for $\mathrm{x}=0.16$. The relative densities $d_{\mathrm{R}}$ for samples here are around $96.5-97.2 \%$, which means the different samples have almost the same porosity.

\begin{tabular}{|l|l|l|l|l|l|}
\hline Sample & $\mathrm{f}$ & $\mathrm{d}\left(\mathrm{g} / \mathrm{cm}^{3}\right)$ & $\mathrm{dR}$ & $\sigma_{\perp}(\mathrm{MPa})$ & $\sigma_{/ /}(\mathrm{MPa})$ \\
\hline $\mathrm{x}=0.24$ & 0.05 & 6.68 & $96.8 \%$ & $/$ & $/$ \\
\hline $\mathrm{x}=0.22$ & 0.03 & 6.65 & $96.9 \%$ & $/$ & $/$ \\
\hline $\mathrm{x}=0.20$ & 0.11 & 6.63 & $97.2 \%$ & $/$ & $/$ \\
\hline $\mathrm{x}=0.18$ & 0.06 & 6.53 & $96.5 \%$ & $/$ & $/$ \\
\hline $\mathrm{x}=0.16$ & 0.11 & 6.51 & $96.6 \%$ & 65 & 60 \\
\hline $\mathrm{x}=0.16$ ingot & $/$ & $/$ & $/$ & 40 & 10 \\
\hline
\end{tabular}

Table 1: List of orientation factor $f$, density $d$, relative density $d_{\mathrm{R}}$,compression strength $\sigma_{\perp}$ and $\sigma_{\| /}$.

The low-magnification FESEM image for $\left(\mathrm{Bi}_{0.16} \mathrm{Sb}_{84}\right)_{2} \mathrm{Te}_{3}$ fractured normal to the pressing direction (Figure $2 \mathrm{a}$ ) reveals that a large number of small particlesare randomly embedded among the particles with micron dimension. A high-magnification FESEM image (Figure 2b) demonstrates that thesmall particles are around the size of 30-80 $\mathrm{nm}$. The low-magnification FESEM image for $\left(\mathrm{Bi}_{0.16} \mathrm{Sb}_{84}\right)_{2} \mathrm{Te}_{3}$ fractured parallel to the pressing direction (Figure $2 \mathrm{c}$ ) reveals many small dots embedded among the layered structure. The high-magnification FESEM image (Figure 2d) confirms that thesmall particlesare around the size of $30-80 \mathrm{~nm}$ and the thickness of the lamellar structure is in the range of $100-200 \mathrm{~nm}$.

Figure 3 shows the TEM results for $\left(\mathrm{Bi}_{016} \mathrm{Sb}_{84}\right)_{2} \mathrm{Te}_{3}$ sliced normal (Figure 3(a-c)) and parallel (Figure 3(d-h)) to thepressing direction. The low magnification TEM image for $\left(\mathrm{Bi}_{0.16} \mathrm{Sb}_{84}\right)_{2} \mathrm{Te}_{3}$ sliced normal to the pressing direction (Figure $3(\mathrm{a})$ ) demonstrates that many nanoparticles with size of $50-80 \mathrm{~nm}$ existed in the matrix with submicron size

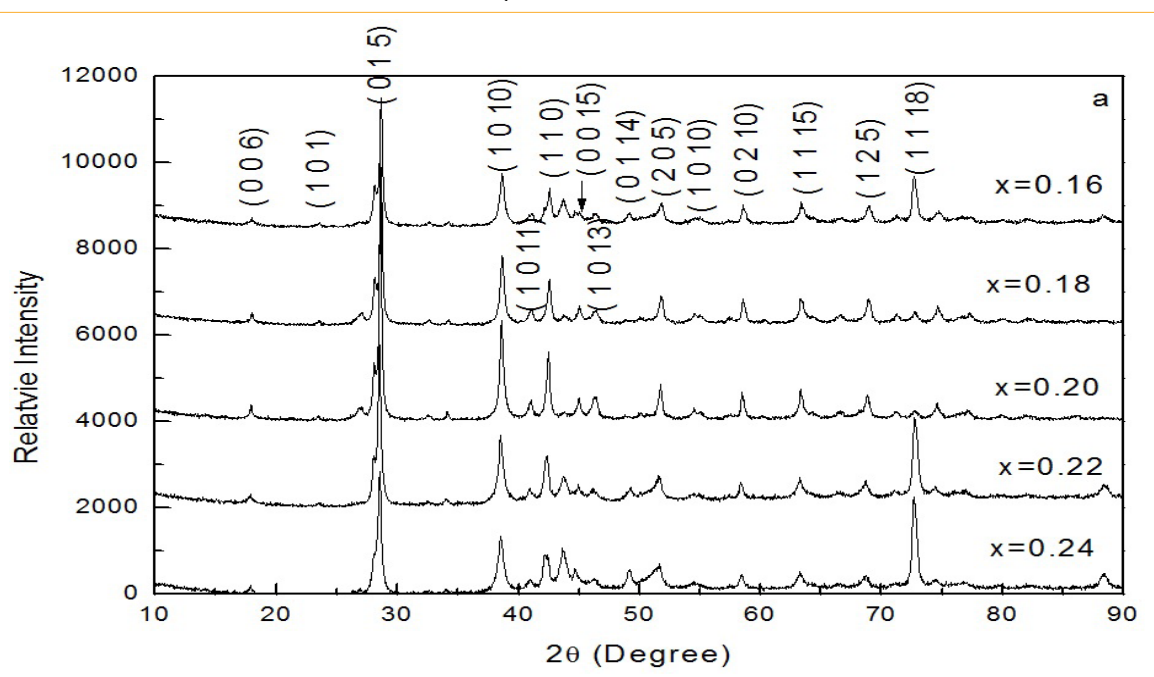

Figure 1: Bulk XRD patterns for $\left(\mathrm{Bi} \mathrm{Sb}_{\mathrm{x}-\mathrm{x}}\right)_{2} \mathrm{Te}_{3}(0.16 \leq \mathrm{x} \leq 0.24)$ sliced normalto the pressing direction. 
Citation: Li D, Qin XY, Zhu XG, Zhang J, Song CJ, et al. (2017) The Anisotropic High Thermoelectric Performance in $\left(\mathrm{Bi}_{\mathrm{x}} \mathrm{Sb}_{1-\mathrm{x}}\right)_{2} \mathrm{Te}_{3}$. Int J Metall Mater Eng 3: 131. doi: https://doi.org/10.15344/2455-2372/2017/131

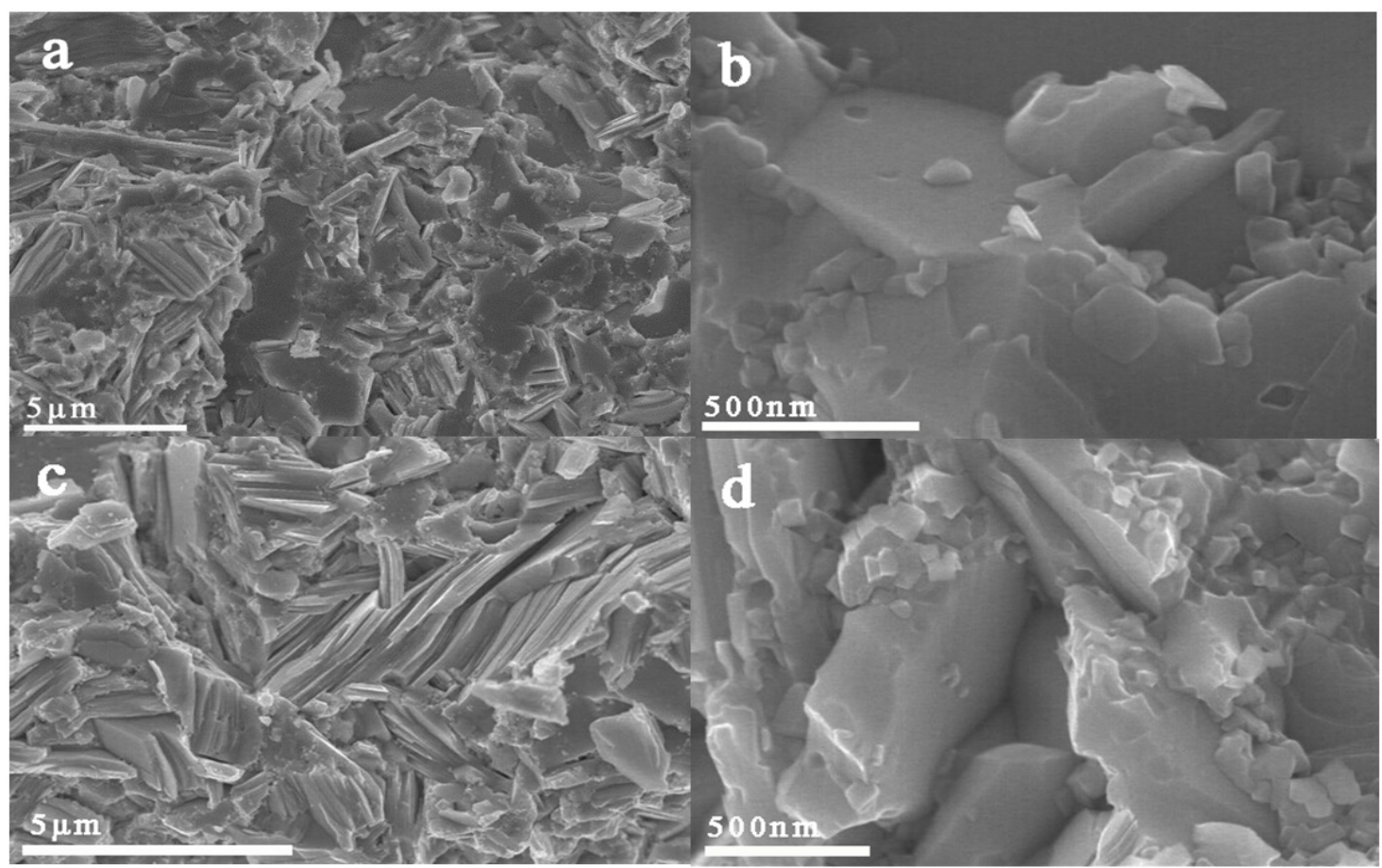

Figure 2: FESEM images of the fracture surfaces of bulk samples for $\left(\mathrm{Bi}_{0.16} \mathrm{Sb}_{0.84}\right)_{2} \mathrm{Te}_{35}$ fractured normal and parallel to the pressing direction

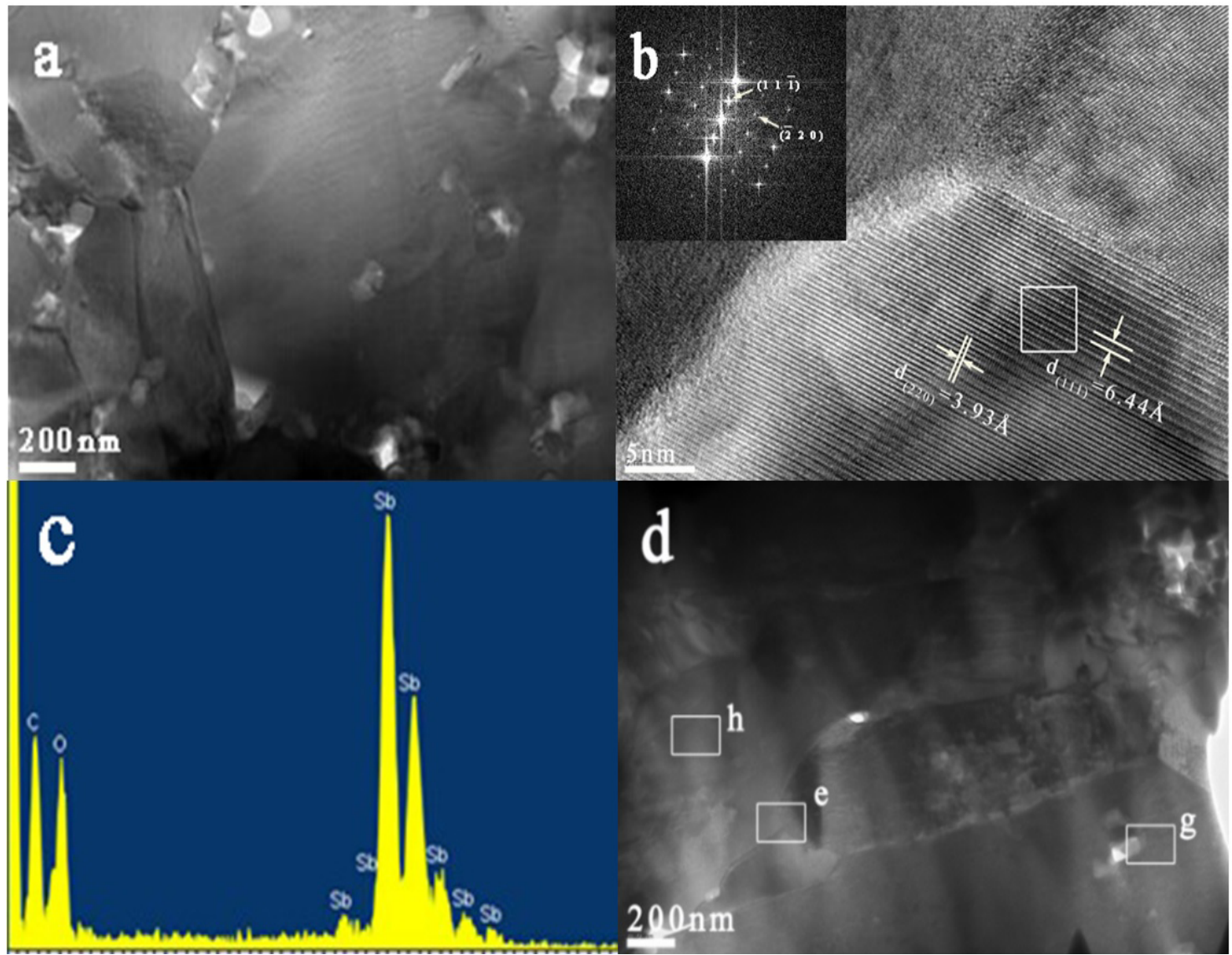

Figure 3: continue... 

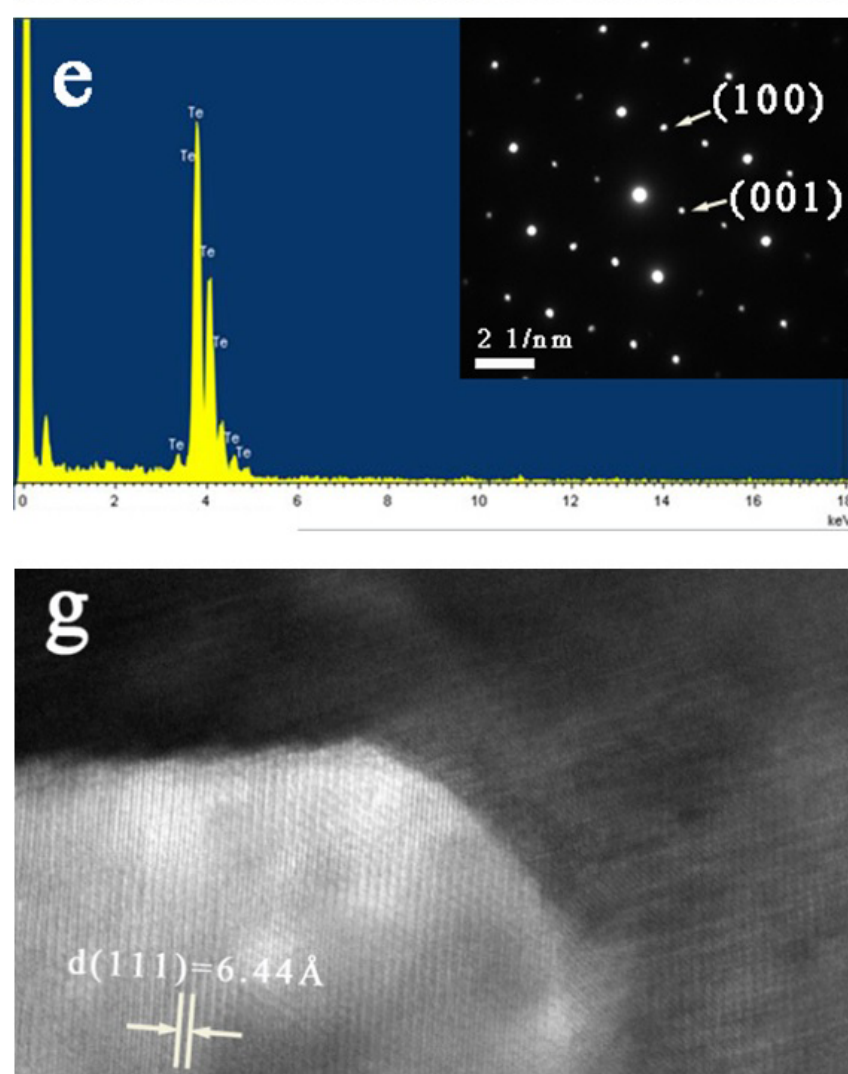

$5 \mathrm{~nm}$

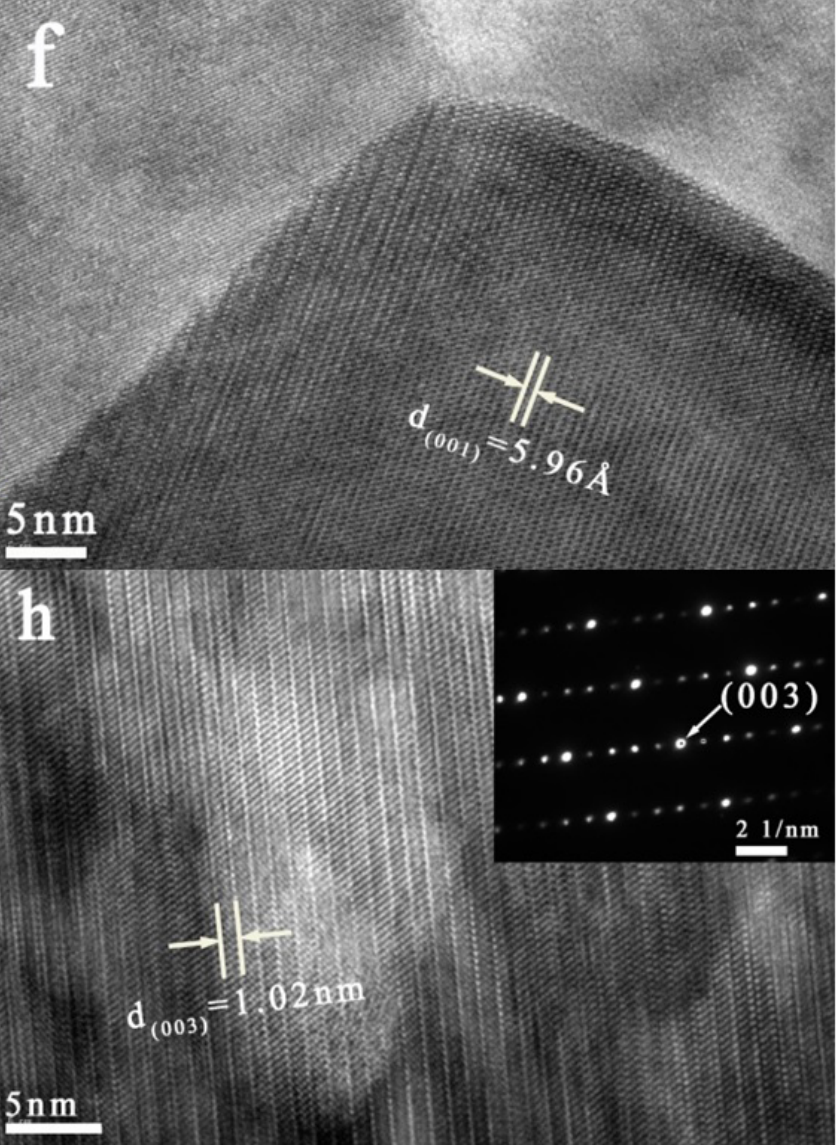

$5 \mathrm{~nm}$

Figure 3: TEM images for $\left(\mathrm{Bi}_{0.16} \mathrm{Sb}_{0.84}\right)_{2} \mathrm{Te}_{3}$ sliced normal (a-c) and parallel to the pressing direction (d-e).

in three forms: along grain boundaries, inside grains and filling the pores. The typical HRTEM image (Figure 3(b)) of an individual nanoparticle reveals that the products are well crystallized and the lattice fringes can be observed clearly. The regular parallel fringe spacing is about $6.44 \AA$ and $3.93 \AA$, which can be assigned to the interplanar spacing of the (lllll $\left.1 \begin{array}{ll}1 & 1\end{array}\right)$ and $\left(\begin{array}{lll}2 & 2 & 0\end{array}\right)$ lattice plane of cubic $\mathrm{Sb}_{2} \mathrm{O}_{3}$. The Fourier transfer diffraction pattern of white square part for nanoparticle is given in the inset of Figure 3(b), confirming that the nanoparticle is $\mathrm{Sb}_{2} \mathrm{O}_{3}$. The energy dispersive $\mathrm{X}$-ray spectroscopic (EDX) patterns (Figure 3(c)) obtained on the nanoparticle confirm that they are compound of element $\mathrm{Sb}$ and $\mathrm{O}$ with the atomic ratio of $\mathrm{Sb}: \mathrm{O}=2: 2.95$. As indicated in the low magnification TEM image of Figure 3(d) for $\left(\mathrm{Bi}_{0.16} \mathrm{Sb}_{84}\right)_{2} \mathrm{Te}_{3}$ sliced parallel to the pressing direction, the dark triangle submicron particles are observed to exist along the grain boundaries, and the bright nanoparticles with size of around $50 \mathrm{~nm}$ in the pore are found in the matrix. The EDX analysis for the dark triangle particle as shown in Figure 3(e) indicates that it is Tellurium. The selected-area electron diffraction (SAED) image taken from the dark triangle particle in theinset of Figure 3(e) confirms that it is a well-crystallized Te crystal. An amplified HRTEM image focusing on theedge of Te particle is presented in Figure 3(f), which indicates that the lattice spacing of about $5.96 \AA$ corresponds to (001) planes ofhexagonal Te. The HRTEM image of bright nanoparticle as shown in Figure 3(g) reveals that the interplanar spacing of about $6.44 \AA$ can be assigned to the (11 1) lattice plane of cubic $\mathrm{Sb}_{2} \mathrm{O}_{3}$. The amplified HRTEM image for matrix is presented in Figure $3(\mathrm{~h})$. The lattice spacing of about $1.02 \mathrm{~nm}$ corresponds to $\left(\begin{array}{lll}0 & 0 & 3\end{array}\right)$ planes of rhombohedral $\left(\mathrm{Bi}_{0.16} \mathrm{Sb}_{84}\right)_{2} \mathrm{Te}_{3}$. SAED image taken from the matrix in theinset of Figure 3(h)shows that spacing distance of $1.02 \mathrm{~nm}$ is a five-layer lamellae with orientation arrangement along the $\left[\begin{array}{lll}0 & 0 & 1\end{array}\right]$ direction. EDX results obtained on the matrix indicate that the atomic ratio for $\mathrm{Bi}: \mathrm{Sb}: \mathrm{Te}$ in $\left(\mathrm{Bi}_{016} \mathrm{Sb}_{84}\right)_{2} \mathrm{Te}_{3}$ is 0.34:1.59:3.

Temperature dependence of electrical resistivity measured normal $\left(\rho_{\perp}\right)$ and parallel $\left(\rho_{\|}\right)$to the pressing direction is plotted in Figure 4(a) and Figure 4(b), respectively. The dependence of $\rho$ on temperature for the samples as shown in Figure 4(a) and Figure 4(b) is similar: the electrical resistivity increases with the increase of temperature, whic hindicates that the materials exhibit metallic-like or degenerate semiconductor behavior. In addition, $\rho$ for $\left(\mathrm{Bi} \mathrm{Sb}_{1 \times}\right) \mathrm{Te}_{3}$ $(0.16 \leq x \leq 0.24)$ decreases with decreasing Bi content. For example, $\rho$ and $\rho$ at room temperature decreases from $1.87 \times 10^{-5} \Omega \mathrm{m}$ and $2.24 \times 10^{-5} \Omega \mathrm{m}$ to $0.86 \times 10-5 \Omega \mathrm{m}$ and $1.08 \times 10-5 \Omega \mathrm{m}$ with decreasing $\mathrm{x}$ from 0.24 to 0.16 , respectively. Moreover, for the same sample,

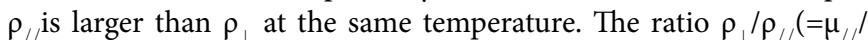
$\left.\mu_{1}\right)$ for $\left.\left(\mathrm{Bi} \mathrm{Sb}_{1-x}\right)\right)_{2} \mathrm{Te}_{3}(0.16 \leq \mathrm{x} \leq 0.24)$ is presented in Figure $3(\mathrm{c})$, which is in the range of $0.72-0.93$ and basically independent on the temperature. The positive values of Seebeck coefficient for $\left(\mathrm{Bi} \mathrm{Sb}_{\mathrm{x}}\right.$. $\left.{ }_{x}\right)_{2} \mathrm{Te}_{3}(0.16 \leq \mathrm{x} \leq 0.24)$ measured normal $\left(\mathrm{S}_{\perp}\right)$ and parallel $\left(\mathrm{S}_{/ \mid}\right)$to the pressing direction determined over the temperature range of $300 \mathrm{~K}$ to $523 \mathrm{~K}$, as shown in Figure 5(a) and Figure 5(b), respectively, means that the major charge carriers in the samples are holes. The Seebeck coefficient for the samples is observed to increase with increasing temperature, and after reaching a maximum value, it shows a decrease with further increase in temperature. This behavior has been reported previously and is probably due to the excitation of minority carrier at 
Citation: Li D, Qin XY, Zhu XG, Zhang J, Song CJ, et al. (2017) The Anisotropic High Thermoelectric Performance in (Bi Sb $\left.{ }_{1-x}\right)_{2}$ Te $_{3}$. Int J Metall Mater Eng 3: 131. doi: https://doi.org/10.15344/2455-2372/2017/131

Page 5 of 8
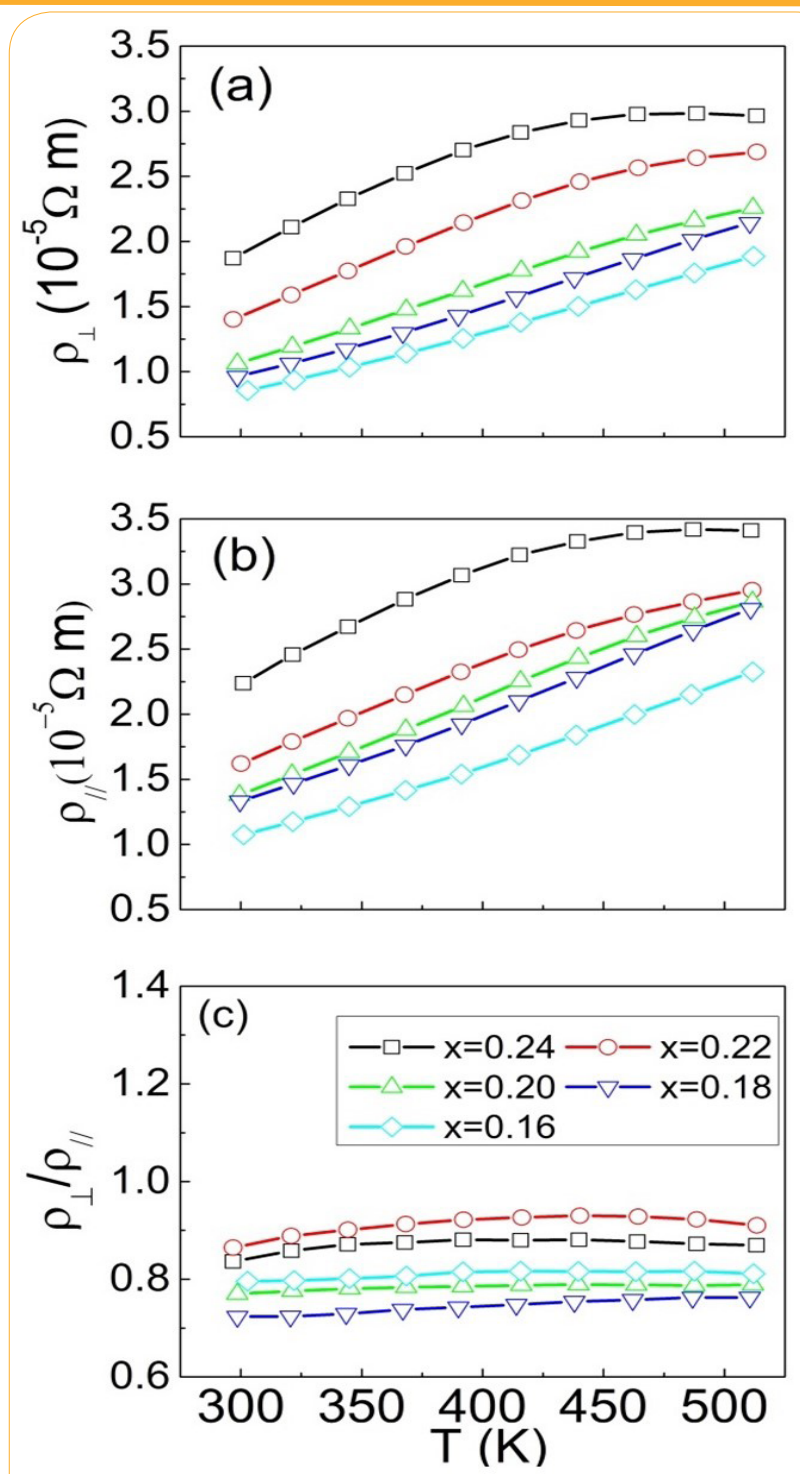

Figure 4: Temperature dependent $(\mathrm{a}, \mathrm{b})$ electric resistivity $\left(\rho_{\perp}, \rho_{/ /}\right),(\mathrm{c})$ ratio of $\rho_{\perp} / \rho$, for $\left(\mathrm{Bi}_{\mathrm{x}} \mathrm{Sb}_{1-\mathrm{x}}\right)_{2} \mathrm{Te}_{3}(0.16 \leq \mathrm{x} \leq 0.24)$

high temperature [6]. The ratio of $S_{\perp}$ to $S$ is presented in Figure 5(c). It can be seen that the ratio of $\mathrm{S}_{\perp}$ to $\mathrm{S}$ for $\left(\mathrm{Bi}_{\mathrm{x}} \mathrm{Sb}_{1-\mathrm{x}}\right)_{2} \mathrm{Te}_{3}(0.16 \leq \mathrm{x} \leq 0.24)$ in the measured temperature range is in the range of 0.9-1.1, which indicates that the Seebeck coefficient for $\left(\mathrm{Bi}_{\mathrm{x}} \mathrm{Sb}_{1-\mathrm{x}}\right)_{2} \mathrm{Te}_{3}(0.16 \leq \mathrm{x} \leq 0.24)$ are isotropic within the experimental error.

The Hall coefficient, $\mathrm{RH}$, at room temperature (RT) is positive for $\left(\mathrm{Bi}_{\mathrm{x}} \mathrm{Sb}_{1-\mathrm{x}}\right)_{2} \mathrm{Te}_{3}(0.16 \leq \mathrm{x} \leq 0.24)$, indicating $p$-type or hole conduction in this system, which agrees with the results of Seebeck coefficient. Assuming parabolic bands and a single band conduction process at $300 \mathrm{~K}$, the carrier concentration, $p$, is estimated from the formula: $p=1 / \mathrm{eRH}$, where e is the carrier charge. The carrier concentrations $p$ are $1.54 \times 1019,2.10 \times 1019,2.76 \times 1019,3.33 \times 1019$ and $3.73 \times 1019$ $\mathrm{cm}^{-3}$ for samples with $\mathrm{x}=0.24,0.22,0.20,0.18$ and 0.16 , respectively (Table 2). Hence, it is the increase incarrier concentration that causes the decrease in electrical resistivity with decreasing bismuth content. The RThole mobilityis calculated from the equation $\mu=1 /(\rho p e)$, andis listed in Table 2. One can see that for the same sample, $\mu_{\perp}$ is larger than $\mu_{/ /}$, and thus the larger $\rho_{/ /}$than that of $\rho_{\perp}$. Conflicting with the Mott formula[13]
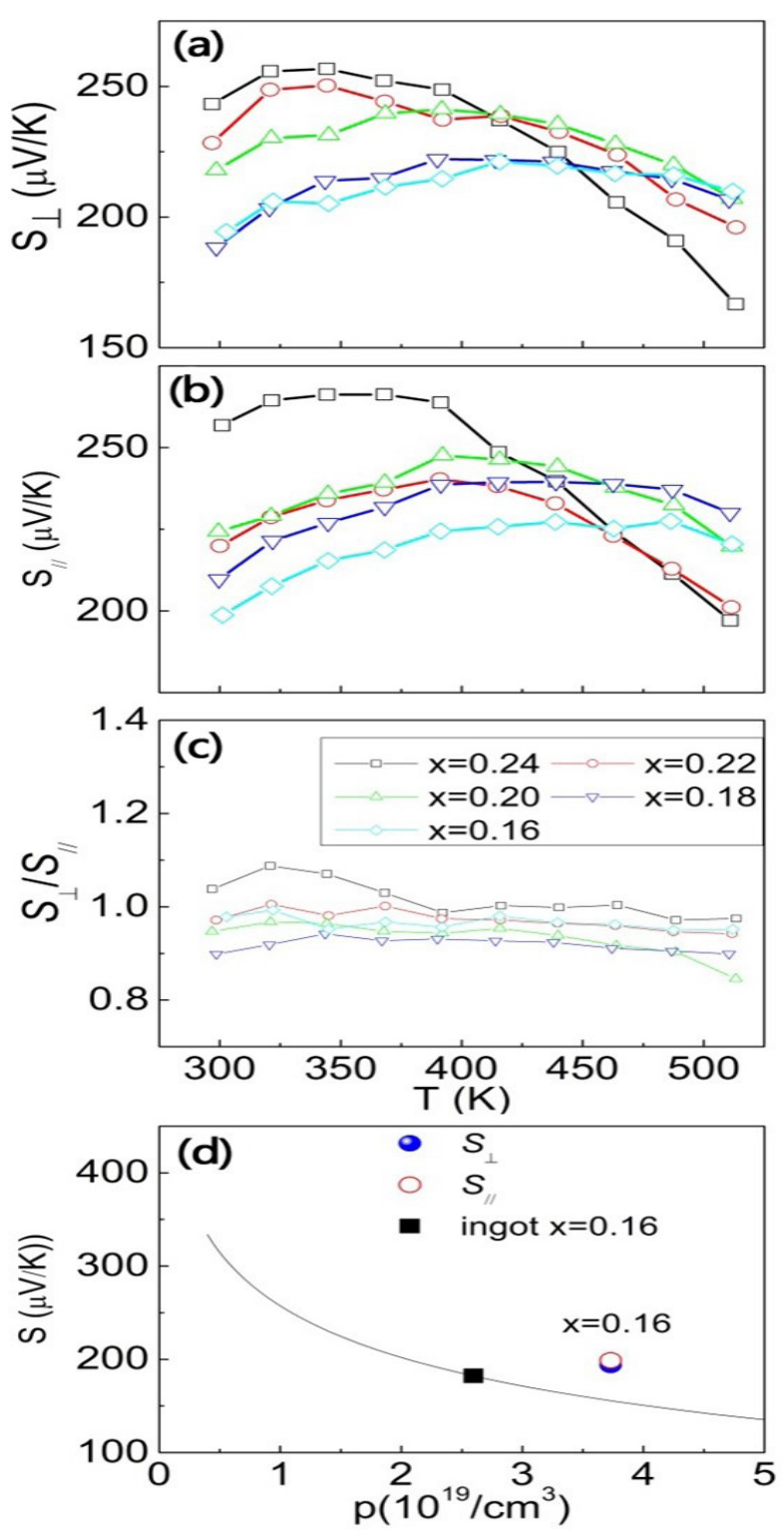

Figure 5: Temperature dependent $(\mathrm{a}, \mathrm{b})$ Seebeck coefficient $\left(\mathrm{S}_{\perp}, \mathrm{S}_{/ /}\right)$, (c) ratio of $S_{1} / S_{1}$, (d) variation of Seebeck coefficient with carrier concentration for $\mathrm{x}=0.16$. Thesolid line is Pisarenko relation for ingot $\left(\mathrm{Bi}_{\mathrm{x}} \mathrm{Sb}_{1-\mathrm{x}}\right)_{2} \mathrm{Te}_{3}$.

$S=\frac{\pi^{2}}{3} \frac{k_{B}}{q} k_{B} \mathrm{~T}\left\{\frac{d \ln (\sigma(E))}{d E}\right\}_{E=E_{F}}$

\begin{tabular}{|l|l|l|l|l|l|}
\hline Sample & $\mu_{\perp}\left(\mathrm{cm}^{2} \mathrm{~V}^{-1} \mathrm{~s}^{-1}\right)$ & $\mu_{/ /}\left(\mathrm{cm}^{2} \mathrm{~V}^{-1} \mathrm{~s}^{-1}\right)$ & $\mathrm{p}\left(\times 10^{19} \mathrm{~cm}^{-3}\right)$ & $\mathrm{r}_{\perp}$ & $\mathrm{r}_{/ /}$ \\
\hline $\mathrm{x}=0.24$ & 217 & 181 & 1.51 & & \\
\hline $\mathrm{x}=0.22$ & 212 & 184 & 2.10 & & \\
\hline $\mathrm{x}=0.20$ & 213 & 160 & 2.76 & & \\
\hline $\mathrm{x}=0.18$ & 196 & 141 & 3.33 & & \\
\hline $\mathrm{x}=0.16$ & 195 & 155 & 3.73 & 1.43 & 1.49 \\
\hline
\end{tabular}

Table 2: List ofroom temperature Hall mobility $\mu$,carrier concentration $p$, and scattering factor $r$ for $\left(\mathrm{Bi}^{\mathrm{x}} \mathrm{Sb}^{1-\mathrm{x}}\right)^{2} \mathrm{Te}^{3}(0.16 \leq \mathrm{x} \leq 0.24)$ 
Citation: Li D, Qin XY, Zhu XG, Zhang J, Song CJ, et al. (2017) The Anisotropic High Thermoelectric Performance in (Bi $\left.\mathrm{Sb}_{1-\mathrm{x}}\right)_{2} \mathrm{Te}_{3}$. Int J Metall Mater Eng 3: 131. doi: https://doi.org/10.15344/2455-2372/2017/131

Page 6 of 8

which tells us that $S$ decreases with increasing $p$, $\mathrm{S}_{/ /}$or $\mathrm{S}_{\perp}$ for $\left(\mathrm{Bi}_{\mathrm{x}} \mathrm{Sb}_{1}\right.$ $\left.{ }_{x}\right)_{2} \mathrm{Te}_{3}(0.16 \leq \mathrm{x} \leq 0.24)$ does not monotonically decrease with increasing $p$. For example, although RT carrier concentration for $\mathrm{x}=0.22$ is 2.10 $\times 1019 \mathrm{~cm}^{-3}$, which is smaller than that $\left(2.76 \times 1019 \mathrm{~cm}^{-3}\right)$ of $\mathrm{x}=0.20, \mathrm{~S}$ for $\mathrm{x}=0.22$ is smaller than that of $\mathrm{x}=0.20$ in the measured temperature range, which means that other mechanisms also work. Due to the existence of $\mathrm{Sb}_{2} \mathrm{O}_{3}$ nanoparticles phase as observed in TEM results, hetero-junction potential barriers (or wells) should be formed at the phase interfaces, which could cause energy-dependent scattering of carriers. The density of state effective mass $m_{d}^{*}$ is calculated based on the measured RT $p=2.60 \times 1019 / \mathrm{cm}_{3}$ and $S=182.1 \mu \mathrm{V} / \mathrm{K}$ for ingot $\left(\mathrm{Bi}_{0.16} \mathrm{Sb}_{0.84}\right)_{2} \mathrm{Te}_{3}$ without nano-inclusions $\left(\mathrm{S}_{0}\right)$ using the equations expressed as follows [14]:

$m_{d}^{*}=\frac{h^{2}}{2 k_{B} T}\left[\frac{p}{4 \pi F_{1 / 2}(\eta)}\right]^{2 / 3}$

$S= \pm \frac{k_{B}}{q}\left[\frac{(r+5 / 2) \mathrm{F}_{r+3 / 2}(\eta)}{(r+3 / 2) \mathrm{F}_{r+1 / 2}(\eta)}-\eta\right]$

$F_{n}(\eta)=\int_{0}^{\infty} \frac{x^{n}}{1+e^{x-\eta}} d x$

$\eta$ is the reduced Fermi energy, $\mathrm{Fn}(\eta)$ is the nth order Fermi integral, $\mathrm{h}$ is Plank constant, $\mathrm{kB}$ is the Boltzmann constant, and $\mathrm{r}$ is scattering parameter of relaxation time. In our calculations, we assume acoustic phonon scattering dominates (i.e., $r=-1 / 2$ ), and the effective mass $\mathrm{md}^{\star}$ is obtained to be $1.01 \mathrm{~m} 0$ (where $\mathrm{m} 0$ is the free electron mass) for $\mathrm{S} 0$, which is close to the reported value of $m_{0}[15]$. Assuming $m_{d}^{*}$ for the nano-composite samples is the same as that of $\mathrm{S}_{0}$ and does not change in different samples, $\mathrm{r}_{\perp}=1.43$ or $\mathrm{r}_{/}=1.49$ at $300 \mathrm{~K}$ can be obtained according to the above eqn (2-4) using the measured $S$ and carrier concentration $(p)$, which indicates that $\mathrm{r}$ values of $\left(\mathrm{Bi}_{0.16} \mathrm{Sb}_{0.84}\right)_{2} \mathrm{Te}_{3}$ embedded with $\mathrm{Sb}_{2} \mathrm{O}_{3}$ are larger than that of $\mathrm{S}_{0}$. This increase in $r$ results in an increase of about $42 \mu \mathrm{V} / \mathrm{K}$ above an expected value in $S$ results in an increase of about $42 \mu \mathrm{V} / \mathrm{K}$ above an expected value in $S$ at $300 \mathrm{~K}$ for the at $300 \mathrm{~K}$ for the samples with $\mathrm{x}=0.16$, as shown in Figure 5(d)(where the solid line is Pisarenko relation [16] for ingot $\left.\left(\mathrm{Bi}_{0.16} \mathrm{Sb}_{0.84}\right)_{2} \mathrm{Te}_{3}\right)$ and shows the dependence of $S$ on $p$ calculated by using Eqs. (2)-(4) and $\mathrm{m}^{\star}=1.01 \mathrm{~m}_{0}$ for ingot $\left.\left(\mathrm{Bi}_{0.16} \mathrm{Sb}_{0.84}\right)_{2} \mathrm{Te}_{3}\right)$.

The effects of temperature on the thermal conductivity ( $\kappa$ and $\left.\kappa_{,}\right)$for $\left(\mathrm{Bi}_{\mathrm{x}} \mathrm{Sb}_{1-\mathrm{x}}\right)_{2} \mathrm{Te}_{3}(0.16 \leq \mathrm{x} \leq 0.24)$ are presentedin Figure $6(\mathrm{a})$ and Figure 6(b), respectively. As seen in Figure 6(a) and Figure 6(b), the temperature dependence behavior of the thermal conductivity for the samples is similar: it decreases with increasing temperature and then increases with further increasing temperature. Such behavior is typical of crystalline materials. The ratio of $\kappa_{\perp}$ to $\kappa_{/ /}$is plotted in Figure 6(c). It can be seen that for $\mathrm{x}=0.24$, the value of $\kappa_{\perp} / \kappa_{\text {, }}$ is around 1 in the whole temperature range investigated, indicating that the thermal conductivity for $\mathrm{x}=0.24$ is isotropic. However, $\kappa_{\perp} / \kappa_{\text {, for }}$ $\left(\mathrm{Bi}_{\mathrm{x}} \mathrm{Sb}_{1-\mathrm{x}}\right)_{2} \mathrm{Te}_{3}(0.16 \leq \mathrm{x} \leq 0.22)$ is in the range of 1.10-1.26. Interestingly, we find that there exists a relation of $\kappa_{\perp} / \kappa_{/}=/(1-f)$ or $\kappa_{\perp}=\kappa_{/} /(1-f)$ in $\left(\mathrm{Bi}_{\mathrm{x}} \mathrm{Sb}_{1-\mathrm{x}}\right)_{2} \mathrm{Te}_{3}$ system, as shown in Figure 6(d). The result implies that the relationship between thermal conductivity and orientation factor $f$ could conform to the rule of mixture as follows

$$
k_{/ /}=k f_{i}+(1-f) k_{\perp}
$$

Where $\kappa_{\mathrm{i} / /}$ is the intrinsic thermal conductivity along c-axis for a single crystal. Formula (5) illustrates that: (a) as $f=1$ (which means that the sample is complete anisotropy in its microstructure, just as a single crystal with c-axis along pressing direction), $\kappa_{\mathrm{p}}=\kappa_{\mathrm{i} / /}$,
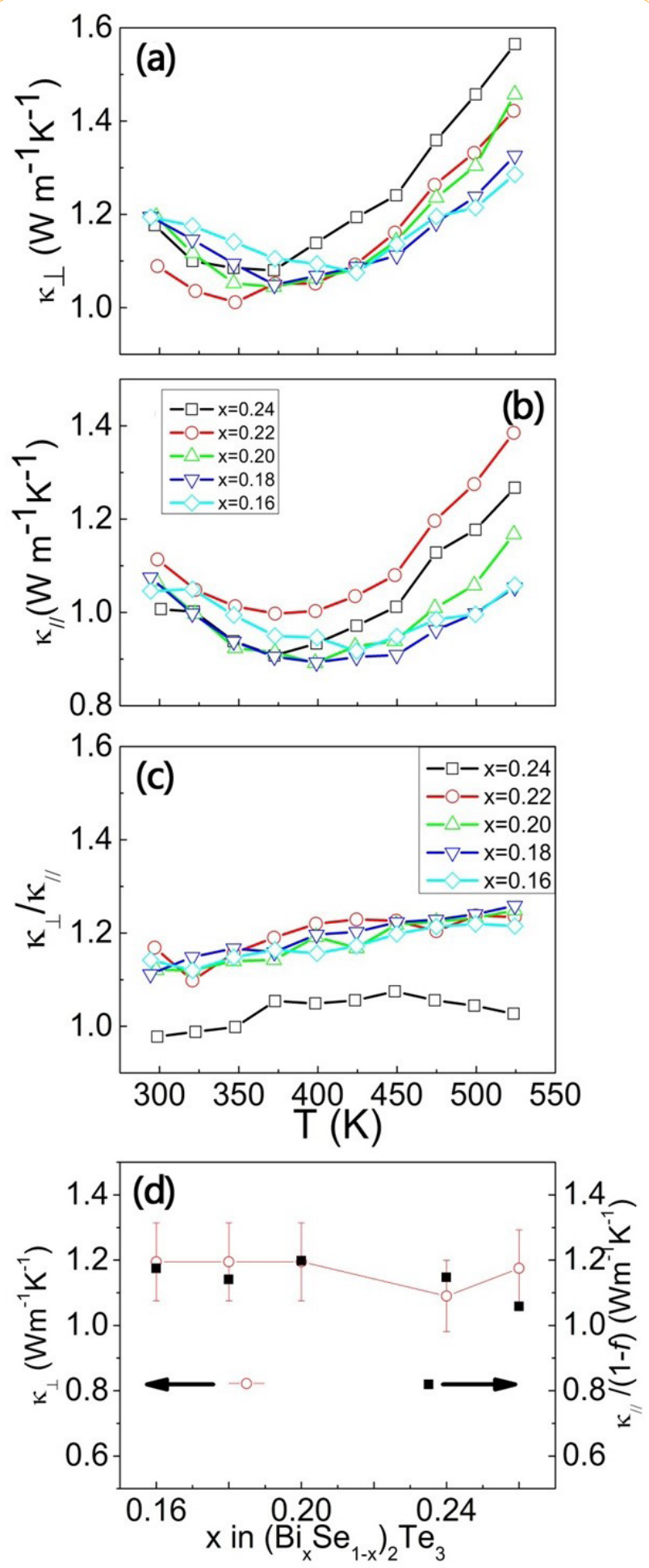

Figure 6: The plot of $(a, b)$ thermal conductivity $\left(\kappa_{\perp}, \kappa_{,}\right),(\mathrm{c})$ ratio of $\kappa_{\perp} / \kappa^{\prime}$ with temperature, $(\mathrm{d})$ plot of $\kappa_{\perp}$ and $\kappa_{/ /} /(1-f)$ with $\mathrm{x}$ in $\left.\left(\mathrm{Bi}_{0.16} \mathrm{Sb}_{0.84}\right)_{2} \mathrm{Te}_{3}\right)$.

indicating formula (5) holds; (b) a $f=0$ (that means the sample is complete isotropy in its microstructure and the thermal conductivity measured in any direction is identical), $\kappa_{/}=\kappa_{\perp}$, indicating formula (5) holds as well; (c) as $\mathrm{f}<<1$, the first term in the right, $f \kappa_{\mathrm{i} / /}$, can be neglected as compared tothe second term $(1-\mathrm{f}) \kappa_{\perp}$, and formula (5) canbe reduced to $\kappa_{\perp}=\kappa_{/} /(1-\mathrm{f})$, which has already been verified by our experimental results (Figure 6(d)); (d) in a more general case, if $0<\mathrm{f}<1$, 
Citation: Li D, Qin XY, Zhu XG, Zhang J, Song CJ, et al. (2017) The Anisotropic High Thermoelectric Performance in (Bi $\left.\mathrm{Sb}_{1-\mathrm{x}}\right)_{2} \mathrm{Te}_{3}$. Int J Metall Mater Eng 3: 131. doi: https://doi.org/10.15344/2455-2372/2017/131

Page 7 of 8

the term $f \mathrm{k}_{\mathrm{i} / /}$ cannot be ignored, then formula (6) can be written as:

$k_{\perp}=\frac{k_{/ /}-f k_{i / /}}{1-f}$

Subtracting the carrier thermal conductivity $(\kappa \mathrm{C})$, expressed as $\kappa_{\mathrm{C}}=\mathrm{L}_{0} \mathrm{~T} / \rho$ (here $\mathrm{L}_{0}$ is the Lorenz number $\left(2.0 \times 10^{-8} \mathrm{~V}^{2} \mathrm{~K}^{-2}\right)$ and $\rho$ is the electrical resistivity $[15,17]$, from $\kappa$, the lattice thermal conductivityin the direction normal $\left(\kappa_{\mathrm{L}, 1}\right)$ and parallel $\left(\kappa_{\mathrm{L} / /}\right)$ to the pressing direction, are obtained as shownin Figure 7(a) and Figure 7(b), respectively.
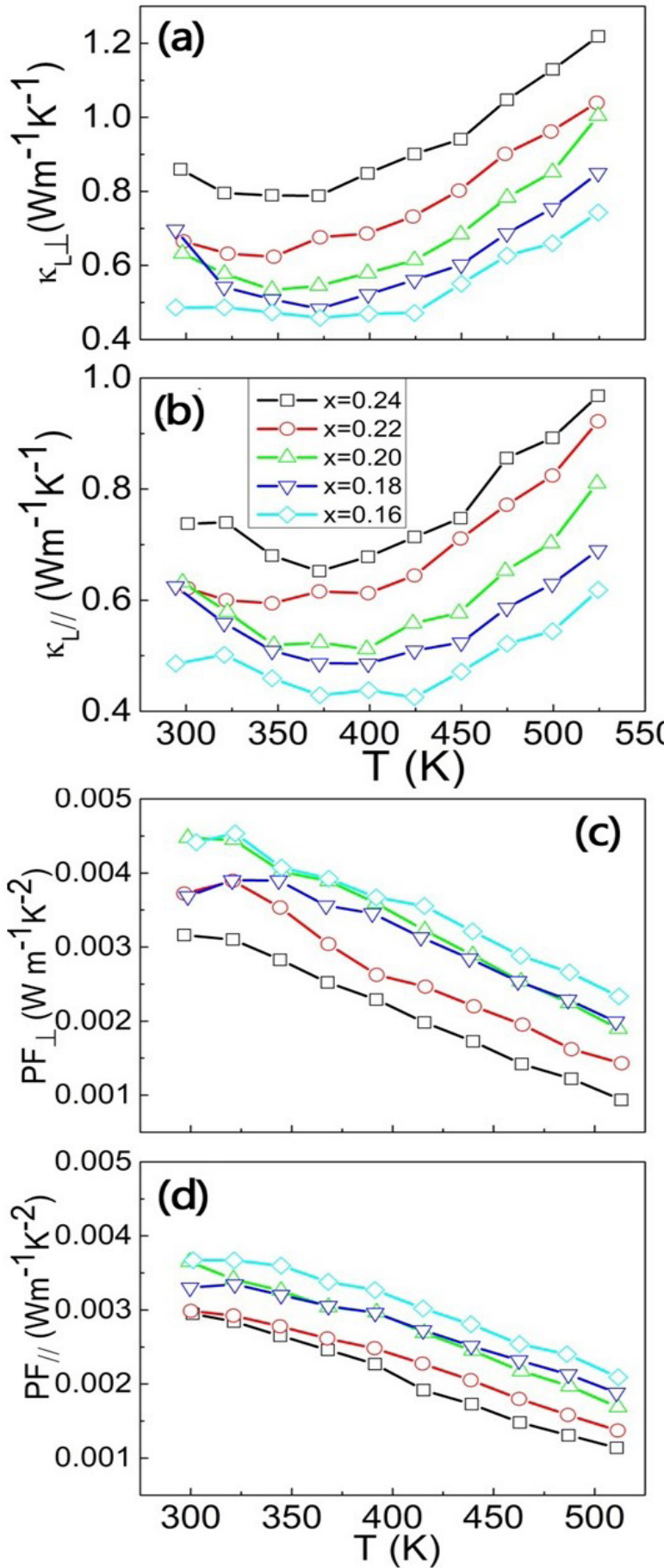

Figure 7: Plot of $(a, b)$ the lattice thermal conductivity $\left(\kappa_{L \perp}, \kappa_{L / /}\right) ;(c, d)$ power factor $\left(\mathrm{PF}_{\perp}, \mathrm{PF}_{/ /}\right)$with temperature.
The reduction of $\kappa_{\mathrm{L} \perp}$ and $\kappa_{\mathrm{L} / /}$ for $\left(\mathrm{Bi}_{\mathrm{x}} \mathrm{Sb}_{1-\mathrm{x}}\right)_{2} \mathrm{Te}_{3}(0.16 \leq \mathrm{x} \leq 0.24)$ with increasing antimony content is attributed to the scattering phonons of point defects due to mass fluctuation. Due to the layered structures, besides many grain boundaries, the intrinsic lattice thermal conductivity is lower in the direction parallel to the pressing direction than thatin the direction normal to the pressing direction, resulting from stronger phonon scattering in the direction parallelto the pressing direction. It should be noted that the thermal conductivity for $\left(\mathrm{Bi}_{\mathrm{x}} \mathrm{Sb}_{1-\mathrm{x}}\right)_{2} \mathrm{Te}_{3}(0.16 \leq \mathrm{x} \leq 0.24)$ in this work is lower than that reported previously, [18] which is due tothe existence of $\mathrm{Sb}_{2} \mathrm{O}_{3}$ nano-inclusions in $\left(\mathrm{Bi}_{\mathrm{x}} \mathrm{Sb}_{1-\mathrm{x}}\right)_{2} \mathrm{Te}_{3}(0.16 \leq \mathrm{x} \leq 0.24)$ matrix.

The calculated power factor $\left(\mathrm{PF}_{\perp}\right.$ and $\mathrm{PF} /$ for $\left(\mathrm{Bi}_{\mathrm{x}} \mathrm{Sb}_{1-\mathrm{x}}\right)_{2} \mathrm{Te}_{3}$ $(0.16 \leq \mathrm{x} \leq 0.24)$ is shown in figure $7(\mathrm{c})$ and figure $(\mathrm{d})$, respectively. Due to the lower $\rho_{\perp}, \mathrm{PF}$ is larger than that of $\mathrm{PF}$ at the same temperature. For example, RT PF is $4.5 \times 10-3 \mathrm{Wm}-1 \mathrm{~K}-2$ for $\mathrm{x}=0.16$, which is larger than that $\left(3.7 \times 10^{-3} \mathrm{~m}^{-1} \mathrm{~K}^{-2}\right)$ of $\mathrm{PF}_{1}$. Based on the data obtained above, the temperature dependence of $\mathrm{ZT}$ and $\mathrm{ZT}$ for $\left(\mathrm{Bi} \mathrm{Sb}_{1 \times}\right)_{2} \mathrm{Te}_{3}$ $(0.16 \leq x \leq 0.24)$ are shown in Figure 8(a) and Figure 8(b), respectively. As seen in Figure $8(\mathrm{a} \& \mathrm{~b})$, the temperature behavior of ZT for the samples is similar: it increases with increasing temperature, and after reaching a maximum, $\mathrm{ZT}$ value decreases with further increasing temperature. Although $\mathrm{PF}$ for $\mathrm{x}=0.20,0.18$ and 0.16 is lower than that
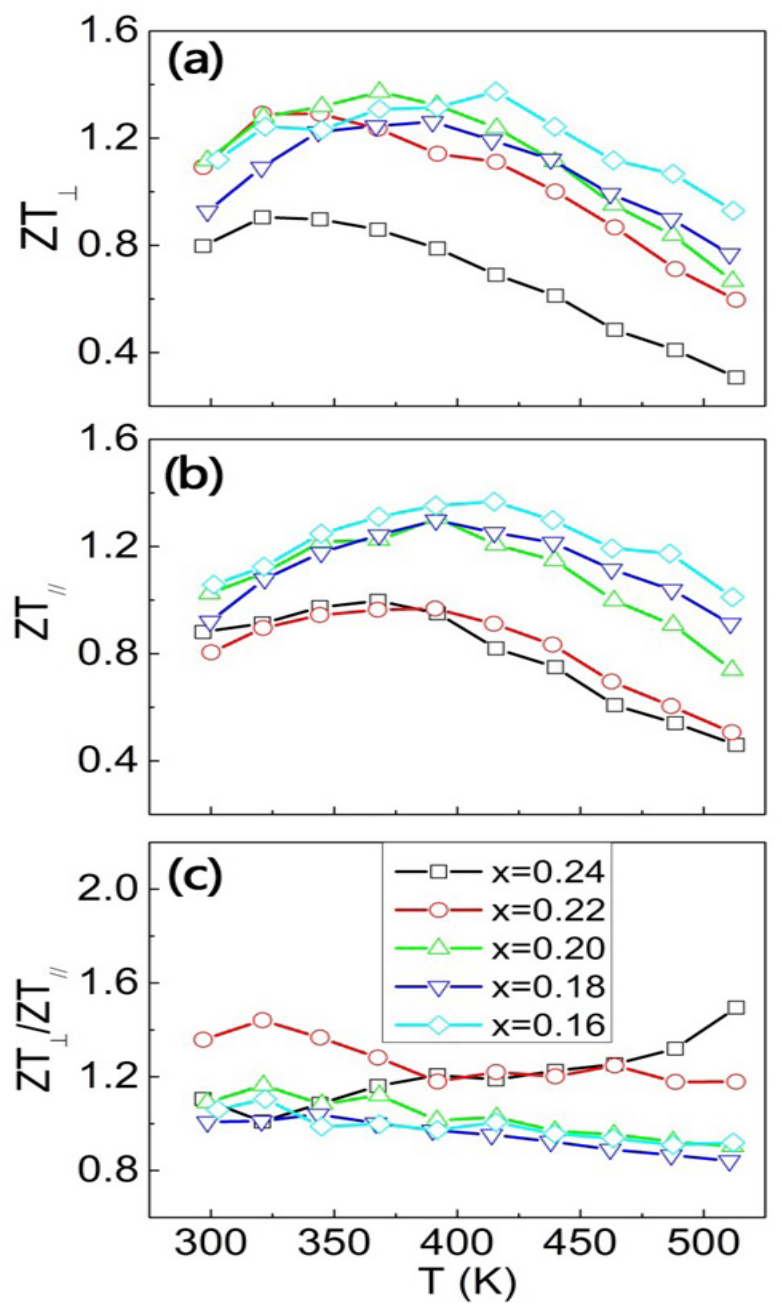

Figure 8: Temperature dependent $(\mathrm{a}, \mathrm{b})$ figure of merit $\left(\mathrm{ZT}_{\perp}, \mathrm{ZT}_{/ /}\right),(\mathrm{c})$ ratio of $\mathrm{ZT}_{\perp} / \mathrm{ZT}_{/ /}$for $\left.\left(\mathrm{Bi} \mathrm{Sb}_{\mathrm{x}}\right)_{1-\mathrm{x}}\right)_{2} \mathrm{Te}_{3}(0.16 \leq \mathrm{x} \leq 0.24)$. 
Citation: Li D, Qin XY, Zhu XG, Zhang J, Song CJ, et al. (2017) The Anisotropic High Thermoelectric Performance in (Bi $\left.\mathrm{Sb}_{1-\mathrm{x}}\right)_{2} \mathrm{Te}_{3}$. Int J Metall Mater Eng 3: 131. doi: https://doi.org/10.15344/2455-2372/2017/131

Page 8 of 8

is lower than that of $\mathrm{PF}_{\perp}$ in the whole temperature range investigated, $\mathrm{ZT}$ for $\mathrm{x}=0.20,0.18$ and 0.16 have no significant differences in the two measured directions as seen in Fig. 8(c), due to its lower thermal conductivity. The maximum $\mathrm{ZT}$ is $1.37(368 \mathrm{~K}), 1.26(390 \mathrm{~K})$ and $1.37(415 \mathrm{~K})$ for $\mathrm{x}=0.20,0.18$ and 0.16 , respectively. $\mathrm{ZT}$ reaches the maximum value of $1.30(390 \mathrm{~K}), 1.30(390 \mathrm{~K})$ and $1.37(415 \mathrm{~K})$ for $\mathrm{x}=0.20$, 0.18 and 0.16 , respectively. Specially, for $\left(\mathrm{Bi}_{0.16} \mathrm{Sb}_{0.84}\right)_{2} \mathrm{Te}_{3}$ its peak ZT in the two directions both reaches 1.37. In addition, the compression strength $\sigma$ for $\left(\mathrm{Bi}_{0.16} \mathrm{Sb}_{0.84}\right)_{2} \mathrm{Te}_{3}$ is $60 \mathrm{MPa}$ and $65 \mathrm{MPa}$ in the direction parallel $\left(\sigma_{\mu}\right)$ and normal $\left(\sigma_{\perp}\right)$ to the pressing direction, respectively as seen in Table 1, which is 6 folds and 1.6 times as larger as that of commercial ingot parallel and normal to the directional solidification direction (See details in supplementary materials). The isotropic superior thermoelectric performance obtained for $\left(\mathrm{Bi}_{0.16} \mathrm{Sb}_{0.84}\right)_{2} \mathrm{Te}_{3}$ with good mechanical properties supplies the possibility to meet the requirements of large scale applications.

\section{Conclusions}

$\left(\mathrm{Bi}_{\mathrm{x}} \mathrm{Sb}_{1-\mathrm{x}}\right)_{2} \mathrm{Te}_{3}(0.16 \leq \mathrm{x} \leq 0.24)$ bulk samples are prepared by the melting method, mortar type grinding and spark plasma sintering technique. Due to the isotropic microstructure, highly isotropic resistivity $\left(\rho_{\perp} / \rho=0.72-0.93\right)$ and thermal conductivity $\left(\kappa_{\mathrm{n}} / \kappa_{\mathrm{p}}=1.0-1.26\right)$ of $\left(\mathrm{Bi}_{\mathrm{x}} \mathrm{Sb}_{1-\mathrm{x}}\right)_{2} \mathrm{Te}_{3}$ are obtained. Moreover, an empirical equation $\mathrm{k} \approx$ $\mathrm{k}_{\|} /(1-f)$ holds between the thermal conductivity and orientation factor, suggesting validity of the rule of mixture. As a result, the high figure of merit in both measured directions is obtained. Specifically, the maximum ZT of 1.37 (at $417 \mathrm{~K}$ ) are achieved in both measured directions by simultaneously lowering $\kappa$ from enhanced phonon scattering due to $\mathrm{Sb}_{2} \mathrm{O}_{3}$ nano-inclusions and elevated $S$ via intensified energy filtering effect attributed from the interphase potentials. In addition, $\left(\mathrm{Bi}_{\mathrm{x}} \mathrm{Sb}_{1-\mathrm{x}}\right)_{2} \mathrm{Te}_{3}$ sample also shows good mechanical properties. The superior thermoelectric performance obtained for $\left(\mathrm{Bi} \mathrm{Sb}_{1 \times}\right)_{2} \mathrm{Te}_{3}$ with good mechanical properties supplies the possibility to meet the requirements of large scale applications.

\section{Competing Interests}

The authors have no competing interests with the work presented in this manuscript.

\section{Author Contributions}

All the authors substantially contributed to the study conception, the acquisition of results, and the interpretations as well as drafting the manuscript.

\section{Acknowledgements}

We greatly thank X. G. Zhu for his help in the analysis of TEM. We acknowledge the funding support from the Natural Science Foundation of China under grant No. 51672278, 11674322 and 11374306, AnHui Provincial Natural Science Foundation (No. 1608085MA17 and 1408085QB45) and Institute of Solid State Physics (2016DFS01).

\section{References}

1. Rowe DM (2006) Thermoelectric Handbook: Macro to Nano, Taylor \& Francis Group.

2. Hu LP, Zhu TJ, Wang YG, Xie HH, Xu ZJ, et al. (2014) Shifting up the optimum figure of merit of $p$-type bismuth telluride-based thermoelectric materials for power generation by suppressing intrinsic conduction. Asia Mater 6: e88.
3. Goldsmid HJ (1964) Thermoelectric Refrigeration; Plenum Press: NewYork.

4. Nolas GS, Sharp J, Goldsmid HJ (2001) Thermoelectrics: Basic Principles and New Materials Developments; Springer Series in Material Science Springer: Berlin, 45, pp111-130.

5. Drabble JR, Goodman CHL (1985) Chemical bonding in bismuth telluride. J Phys Chem Solids 5: 142-144.

6. Kim Dh, Kim C, Heo SH, Kim H (2011) Influence of powder morphology on thermoelectric anisotropy of spark-plasma-sintered $\mathrm{Bi}$-Te-based thermoelectric materials. Acta Mater 59: 405-411.

7. Zhang YC, Day T, Snedaker ML, Wang H, Krämer S, et al. (2012) A Mesoporous Anisotropic n-Type $\mathrm{Bi}_{2} \mathrm{Te}_{3}$ Monolith with Low Thermal Conductivity as an Efficient Thermoelectric Material. Adv Mater 24: 50655070 .

8. Yan X, Poudel B, Ma Y, Liu WS, Joshi G, et al. (2010) Experimental Studies on Anisotropic Thermoelectric Properties and Structures of n-Type Bi2Te2.7Se0.3. Nano Lett 10: 3373-3378.

9. Caillat T, Gailliard L, Scherrer H, Scherrer S (1993) Transport properties analysis of single crystals $\left(\mathrm{Bi}_{\times} \mathrm{Sb}_{1-x}\right)_{2} \mathrm{Te}_{3}$ grown by the traveling heater method. J Phys Chem Solids 54: 575-581.

10. Poudel B, Hao Q, Ma Y, Lan YC, Minnich A, et al. (2008) High-thermoelectric performance of nanostructured bismuth antimony telluride bulk alloys. Science 320: 634-638.

11. Ma Y, Hao Q, Poudel B, Lan YC, Yu B, et al. (2008) Enhanced Thermoelectric Figure-of-Merit in p-Type Nanostructured Bismuth Antimony Tellurium Alloys Made from Elemental Chunks. Nano Lett 8: 2580-2584.

12. Lotgering FK (1959) Topotactical reactions with ferrimagnetic oxides having hexagonal crystal structures-I. J Inorg Nucl Chem 9: 113-123.

13. Cutler M, Mott NF (1969) Observation of Anderson Localization in an Electron Gas. Phys Rev 181: 1336.

14. Peng $B$, Zhang $H$, Shao $H, X u ~ Y$, Zhang $X$ (2016) Low lattice thermal conductivity of stanene. Sci Rep 6: 20225

15. Li JH, Tan Q, Li JF, Liu DW, Li F, et al. (2013) BiSbTe-Based Nanocomposites with High ZT: The Effect of SiC Nanodispersion on Thermoelectric Properties. Adv Funct Mater 23: 4317-4323.

16. Jaworski CM, Kulbachinskii V, Heremans JP (2009) Resonant level formed by tin in $\mathrm{Bi}_{2} \mathrm{Te}_{3}$ and the enhancement of room-temperature thermoelectric power. Phys Rev B 80: 233201.

17. Dresselhaus MS, Chen G, Tang MY, Yang R, Lee H, et al. (2007) New Directions for Low-Dimensional Thermoelectric Materials. Adv Mater 19: 1043-1053.

18. Li D, Sun RR, Qin XY (2011) Thermoelectric properties of p-type $\left(\mathrm{Bi}_{2} \mathrm{Te}_{3}\right)$ $x\left(\mathrm{Sb}_{2} \mathrm{Te}_{3}\right)_{1 \times x}$ prepared by spark plasma sintering. Intermetallics 19: 20022005 . 